\title{
ETNICIDADE, MARKETING E EMPREENDEDORISMO: ENTREVISTA COM MARILYN HALTER
}

\author{
Por Ana Cristina Braga Martes \\ Professora de Sociologia da FGV-EAESP \\ E-mail: acbmartes@fgvsp.br
}

Marilyn Halter é professora de História na Universidade de Boston, diretora do American and New England Studies Program e pesquisadora associada do Institute on Culture, Religion and World Affairs, dirigido pelo sociólogo Peter Berger. Suas áreas de especialização são imigração, raça e etnicidade, com foco em empreendedorismo étnico e cultura do consumo. Halter é autora de várias publicações, inclusive dos livros Between Race and Ethnicity: Cape Verdean-American Immigrants, 1860-1965 (Urbana, IL: University of Illinois Press, 1993), New Migrants in the Marketplace: Boston's Ethnic Entrepreneurs (Amherst, MA: University of Massachusetts Press, 1995) e Shopping for Identity: The Marketing of Ethnicity (New York: Schocken Books, 2000).

A obra Between Race and Ethnicity é baseada num estudo etnográfico de imigrantes cabo-verdianos na Nova Inglaterra e traz uma interessante discussão sobre o conceito de raça, no que tange às concepções populares sobre o negro americano e à teoria do processo de assimilação dos imigrantes na América, elaborada a partir dos trabalhos do sociólogo norte-americano Robert Park (1864-1944). O livro New Migrants in the Marketplace reúne pesquisas empíricas realizadas na área metropolitana de Boston, com vários grupos de imigrantes, tais como dominicanos, haitianos e gregos, com o intuito de traçar um panorama atualizado das atividades empreendedoras organizadas por esses grupos, sempre ancoradas em redes de solidariedade.A obra destaca as dificuldades advindas da situação de imigração - inclusive a não-documentação - e as saídas encontradas pelos empreendedores étnicos para superar tais dificuldades. Shopping for Identity, o terceiro livro de Halter (resenhado na RAE, v. 41, n. 3, p. 100-101, 2001), destaca a "revivescência étnica" iniciada nos anos 1980 e sua interface com o consumo de bens identificados com um sentimento difuso de raiz e pertencimento a grupos sociais específicos, numa fase de produção marcadamente pós-fordista.

A entrevista que se segue, concedida pela autora quando esteve no Brasil participando de um evento ocorrido na EAESP em julho de 2006, aborda, com mais detalhes e profundidade, as relações entre marketing, etnicidade, migrações internacionais e empreendedorismo, temas com os quais Halter vem trabalhando na Universidade de Boston.

Por que estudar a relação entre marketing e etnicidade? Uma vez que seu livro Shopping for Identity: The Marketing of Ethnicity representou um trabalho pioneiro nessa direção, gostaríamos de saber como surgiu a idéia de escrevê-lo.

O livro surgiu num "momento de inspiração". Provavelmente há dez anos ou mais, eu estava me preparando para ir ao trabalho e quis saber se precisaria levar meu guarda-chuva, porque na Nova Inglaterra o tempo muda sempre. Então liguei a TV no Weather 
Channel e nada se falava sobre as condições do tempo. Apareciam imagens, fotografias de imigrantes chegando à ilha de Ellis, na cidade de Nova York (no chamado posto de recepção para imigrantes), tiradas pelo fotógrafo Louis Hine, com o qual estou tão familiarizada porque ilustrou meus livros e de outros colegas. Então, concluí: estou no canal errado. Conferi, mas era mesmo o Weather Channel. No entanto, não havia narração, somente música de fundo, e, em seguida, o programa passou a mostrar cenas do East Side de Nova York, nos anos 1920 e 1930, com as comunidades de imigrantes. Continuei intrigada: será mesmo o Weather Channel? Finalmente, uma voz surgiu, e pude então concluir que se tratava de uma propaganda da Trans World Airlines, sobre vôos da TWA para a Europa. Tratava-se de uma propaganda cuja mensagem principal era "retorne às suas raízes", e esse foi meu momento de inspiração: ali estava uma grande corporação norte-americana tentando atrair clientes por meio de um inusitado apelo às origens étnicas e migratórias dos consumidores. Na mesma semana em que assisti a essa propaganda, eu estava lendo a revista Irish America-, pois na época estava fazendo uma pesquisa sobre comunidades de imigrantes -, e havia uma grande foto de propaganda da Northwest Airlines, uma empresa aérea diferente, mas que também trazia a mensagem: "Retorne às suas origens".

Então, eu estava preparada, e naturalmente isso não surgiu do nada. $\mathrm{Na}$ verdade, eu vinha pesquisando seriamente a relação entre imigrantes e management, do ponto de vista dos proprietários e profissionais em Administração com origens imigratórias. Como especialista em estudos americanos, meu foco tem sido o de compreender a relação entre cultura e identidade, e tenho interesse em cul- tura de consumo como parte da cultura popular da sociedade americana. E percebi que essa relação entre etnicidade e marketing poderia funcionar em ambos os sentidos: não somente em termos dos proprietários de negócios étnicos, mas também dos consumidores, sejam imigrantes ou etnoamericanos. Neste último caso, perguntava-me sobre o papel que as empresas e proprietários desempenhariam e sua relação com o mercado de consumo.

Relacionada a isso estava minha interpretação do que chamamos de "ethnic revival", que então tomava corpo nos Estados Unidos, e que estava mais relacionado aos descendentes de imigrantes do que à população de imigrantes propriamente. Sua origem estava nos anos 1970, como resposta aos movimentos de grupos minoritários - Black Pride, afro-americanos -, e nos remetia de volta aos anos 1960, quando surgiram os movimentos pelos direitos civis dos afro-americanos, mexicano-americanos ou chicanos e americanos nativos. Todos esses movimentos tinham em comum a luta por direitos civis, e então, nos anos 1990, alguns dos descendentes de europeus imigrantes brancos reagiram, afirmando: "Nós também temos nosso orgulho". E também eles começaram a celebrar suas próprias raízes. Inicialmente parecia ser uma reação conservadora, contra os negros. O que os imigrantes brancos diziam era: " $\mathrm{E}$ nós? Fomos da classe operária, trabalhamos duro, ninguém reconhece a qualidade de nossas raízes e poder". Então tinha uma conotação politicamente retrógrada, e todos pensavam que isso seria algo passageiro. Mas, os etnoamericanos - independentemente de serem imigrantes, mas que mantiveram interesse em encontrar suas raízes - estavam sendo chamados a voar pela TWA ou Northwest para a Irlanda, de modo que isso não poderia mais ser somente um movimento de reação. Ele havia se transformado e passou a atrair amplamente muitos setores da população. Assim, em vez de desaparecer, ocorreu o contrário: nas décadas seguintes os norte-americanos passaram a encontrar cada vez mais maneiras de celebrar suas heranças culturais, aprendendo suas línguas originais, tomando aulas de dança gaélica, sapateado, música e, certamente, culinária.

Qual é o sentido preciso que você atribui a estes dois termos, "marketing" e "etnicidade", quando aborda a relação entre eles?

Posso dar uma definição de etnicidade, mas, para ser sincera, nunca me pediram para definir "marketing". Não estou certa de como eu o definiria. Deixe-me começar pelo primeiro. $\mathrm{O}$ termo "etnicidade" (ou "grupo étnico") é muito recente. Foi usado pela primeira vez, nos anos 1940, pela Escola de Sociologia de Chicago, em pesquisas denominadas Yankee City Studies e, mais especificamente, no estudo de uma cidade da Nova Inglaterra, Newburyport (Massachusetts), em que o pesquisador W. Lloyd Warner cunhou o termo "etnicidade", no ano de 1947. Antes disso as pessoas usavam a palavra "raça" ou "nacionalidade". Originalmente "etnicidade" se referia a algo que nascia com a pessoa, mas atualmente trata-se de uma categoria construída socialmente, vinculada a relações históricas e de poder. Há muitas definições diferentes, mas costumo considerar o conceito como uma ascendência compartilhada ou a crença de se ter uma ascendência compartilhada, uma herança cultural comum no interior de um grupo. Os pesquisadores estavam inicialmente interessados em estudos urbanos, mais precisamente em questões urbanas relacionadas à classe social, e como havia uma grande população imigrante em Newburyport, eles ficaram inte- 
ressados na cidade. Posteriormente, quando o termo passou a ser mais amplamente utilizado, começou-se a se falar em etnia italiana, judia, irlandesa, etc. Depois de 1965, quando realmente cresceu - principalmente nos anos 1980 e 1990 - a proporção de latino-americanos, asiáticos e caribenhos nos Estados Unidos, o termo se popularizou definitivamente.

Então, voltando ao meu livro, ele foi concebido numa situação em que a demografia estava mudando, assim como os consumidores e o grande empresariado, devido ao declínio do marketing de massa, característico da produção fordista, após os anos 1970. Portanto, não se tratava mais de encontrar propagandas e produtos mais genéricos para alcançar o maior número de pessoas possível. Com a saturação dos mercados de bens de consumo de massa, houve uma completa revisão: quantas máquinas de lavar se podem vender, se todos já possuem sua máquina de lavar? Foi quando ocorreu uma mudança significativa na visão dos profissionais de marketing, tentando encontrar um modo inovador de captar novos consumidores, que resultou no chamado "marketing segmentado", em que se concebem propagandas e promoções para setores específicos da economia. Por exemplo, é preciso saber o tipo de cerveja que os irlandeses estão bebendo no sul da Califórnia, ou com que idade as pessoas jovens, entre 18 e 25 , irão comprar aquela cerveja, ou ainda se os compradores serão homens ou mulheres. Tratava-se, portanto, de um outro tipo de marketing, o marketing segmentado, com o objetivo de lançar produtos específicos direcionados a grupos étnicos e imigrantes. Isso também explica, em parte, como surgiu a idéia de escrever este livro.

Você considera que essa relação entre marketing e etnicidade seja tão im- portante nos Estados Unidos quanto nos países em desenvolvimento, como o Brasil?

Sem dúvida. Ao chegar a São Paulo, fui tentar conhecer um pouco a cidade, $\mathrm{e}$ passei por uma loja de móveis que se chamava Tribos e dizia: "Móveis étnicos". Certamente havia ali uma idéia, na mente dos profissionais de marketing, para captar o interesse dos consumidores. Eis outro exemplo de minha breve estada na cidade: encontrei uma loja inteira de jóias da região amazônica na cidade de Ubatuba, litoral de São Paulo. Então, hoje, em qualquer parte do mundo pode ser encontrada essa confluência entre Administração e cultura, devido à mídia globalizada, à internacionalização e ao movimento de pessoas e produtos. Não existe praticamente uma única nação intocada por essas dimensões.

Provavelmente você não estava pensando na área de Administração quando escreveu esse livro. Entretanto, é sabido que entre os administradores ele obteve excelente repercussão. Como você explica isso?

Talvez porque essa seja, ainda, uma arena muito nova na área de Administração. Tentar imaginar como alcançar o consumidor étnico ou imigrante se tornou um importante nicho do mercado, e todo mundo foi pego de surpresa. $\mathrm{O}$ primeiro alerta foi dado pelo Censo de 1990, mas nem em 2000 as pessoas estavam preparadas para planejar o marketing de maneira culturalmente específica. Meu livro é um trabalho eminentemente acadêmico, e não sou especializada em Administração. Mas foi interessante observar que, enquanto eu estava fazendo minhas entrevistas com vários diretores corporativos de marketing, cheguei a receber muitas ofertas de trabalho. Uma das grandes empresas de marketing segmentado quis me contratar imediatamente, dizendo que eu poderia me estabe- lecer em Nova York e ganhar muito mais dinheiro do que trabalhando como professora da Universidade de Boston. Isso parece mostrar o quanto eles estão desejando esse tipo de informação. Outro entrevistado, proprietário de uma empresa de marketing em Chicago direcionada especificamente para os consumidores afro-americanos, se autodenominava "antropólogo de marketing". Isso porque há muitas semelhanças entre o que um antropólogo faz numa pesquisa etnográfica e o trabalho que um profissional de marketing deve fazer para tentar imaginar qual é o gosto específico de seus consumidores.

Qual e a ligação que existe entre o livro Shopping for Identity: The Marketing of Ethnicity e os dois outros livros que você escreveu sobre imigração e empreendedorismo étnico? Você poderia dizer também como define "empreendedorismo étnico", uma vez que esse não é um termo muito conhecido no Brasil?

Empreendedorismo étnico se refere a um setor da economia baseado em pequenas e médias empresas, dirigidas por imigrantes e suas famílias. Freqüentemente é relacionado a um negócio familiar, mas não diz respeito apenas a gerações de imigrantes. Talvez seja necessário diferenciar o conceito de "imigrante" do de "étnico". "Imigrante" se refere àqueles que cruzaram uma fronteira internacional: deixaram um país e foram morar em outro, e, portanto, são nascidos no exterior. "Étnico" normalmente se refere a alguém nativo que pode estar na segunda geração de sua ascendência original, por exemplo. Então, “empreendedorismo étnico" pode se referir a uma empresa de imigrantes ou empresa étnica. Alguns dos melhores produtos e serviços direcionados pelo marketing étnico contam com os próprios imigrantes como proprietários. 
Por exemplo, se você observar qualquer festival étnico - atualmente são muito populares nos Estados Unidos -, concluirá que eles realmente mostram uma perfeita combinação entre comércio e cultura, uma vez que contêm música, comida, roupas, desfiles, todas essas expressões de uma etnicidade particular. No entanto, existe uma distância entre as pessoas que organizam um festival como esse e aquelas que negociam quase os mesmos produtos apenas para ganhar dinheiro. Para concluir, no livro sobre empreendedorismo étnico, analisei as questões de ordem administrativa à luz da sociologia. No livro sobre marketing, passei a analisar mais especificamente o ponto de vista do consumidor.

Podemos dizer que uma das conclusões extraídas de seu livro sobre empreendedorismo étnico é que existem diferentes estilos, práticas e concepções de como organizar e desenvolver uma empresa, e que essas características variam de acordo com a cultura de origem, independentemente do contexto institucional de recepção? Certamente. Nas pesquisas sobre imigrantes empresários na área de Boston, encontramos diferentes grupos: asiáticos, gregos, judeus da antiga União Soviética, cabo-verdianos e dominicanos. Existe uma razão para se criarem essas empresas: elas são uma resposta às restrições ocupacionais e às resistências institucionais impostas aos imigrantes. Assim, eles estão se adaptando ao encontrar maneiras de contornar o mainstream formal da economia institucionalizada dos Estados Unidos. Por exemplo, muitos dos bancos nos Estados Unidos não concedem empréstimos a estrangeiros. Talvez os imigrantes queiram conseguir emprego, mas isso requer que eles falem inglês e eles não aprenderam inglês ainda. Dessa forma, a saída é iniciar seus próprios negócios, especialmente se eles estiverem vendendo produtos e serviços para seus compatriotas. Com isso, não é tão necessário falar a língua, e, em segundo lugar, eles se apóiam em suas redes étnicas e em sua economia étnica para conseguir os fundos para iniciar seu negócio. Finalmente, eles se apóiam nos membros de sua comunidade étnica para definir a localização do seu negócio. Então, eles iniciam operando na margem, fora do sistema norte-americano, mas com o tempo tendem a se adaptar. Ao aprenderem as práticas empresariais americanas, os mais bem-sucedidos conseguem ultrapassar o campo étnico. São capazes não apenas de dar continuidade à empresa, mas também de expandir o negócio, tomar empréstimos de um banco formal e começam a vender para pessoas além de sua vizinhança.

Em sua opinião, por que os grupos étnicos apresentam graus tão diferenciados quanto à capacidade de desenvolver o empreendedorismo? Como explicar, por exemplo, a alta taxa de pequenas empresas entre os imigrantes asiáticos?

Certamente existe um diferencial no ritmo de criação de novas empresas que depende da nacionalidade, assim como um diferencial na taxa de sucesso. Certos grupos de imigrantes são inicialmente muito mais voltados para o empreendedorismo do que outros. Mas seria simplista dizer algo tão abrangente e genérico como "os hispânicos são muito menos voltados ao empreendedorismo do que os asiáticos", por exemplo. Se olharmos para a categoria hispânica, veremos que há uma grande variação intragrupo, uma diversidade interna entre a população latina. O setor cubano tem obtido mais sucesso com empresas e administração do que o setor mexicano, por exemplo.
Em Miami certamente. Mas em outros estados norte-americanos também?

Certamente na Flórida os cubanos têm tido sucesso de maneira fenomenal. Alcançaram tanto sucesso como empresários que atualmente dirigem grandes fábricas e outros tipos de empresas corporativas, além das pequenas empresas tradicionais de imigrantes. Mas sua história da imigração é diferente. Nos anos 1950 os cubanos eram imigrantes ricos e, ao mesmo tempo, receberam apoio de programas para refugiados. Os mexicanos não receberam o mesmo tipo de apoio por parte dos Estados Unidos nem contavam com recursos próprios ao desembarcarem no país. Há também o que chamamos de "recursos sociais" ou "recursos culturais" que os imigrantes levam com eles ao emigrarem. Não se trata de meios financeiros nem econômicos, mas de recursos culturais, sociais e habilidades especificas. Por exemplo, os grupos se beneficiam muito quando já possuíam no país de origem um legado cultural sobre associações de crédito rotativo. É uma prática cultural que trazem como eles, por já estar enraizada no país de origem. Os coreanos e os japoneses têm essa característica, assim como os chineses. É um processo muito simples, também chamado de indigenous banking: todo compatriota oferece, normalmente a cada semana, uma quantia para um fundo comum, e esse fundo de recursos é delegado a uma pessoa, que passa um turno nessa função. É uma forma de auto-ajuda coletiva, imposta pelo fato de não poderem tomar empréstimos em bancos formais. Quando a rede é forte, quando a associação de empréstimo funciona bem, é muito mais provável que aquela empresa de imigrantes seja bem sucedida. Observe que, dentro da população asiática, os coreanos têm tido muito 
sucesso com pequenas empresas, ao contrário dos filipinos. Eles não têm essa mesma tradição cultural de associação de crédito rotativo. Suas redes comunitárias de co-étnicos não são tão bem desenvolvidas.

E quanto aos demais grupos? Você considera que existe uma especificidade cultural entre os lusófonos na Nova Inglaterra (açorianos, brasileiros e cabo-verdianos) que você estudou? E entre os hispânicos/latinos e brasileiros?

Inicialmente fui atraída a pesquisar os imigrantes cabo-verdianos, em parte porque eu estava vivendo no sudeste de Massachusetts, onde existe uma grande população de cabo-verdianos, e estava muito interessada em questões de identidade racial e étnica. Os cabo-verdianos foram o primeiro grupo de imigrantes africanos a fazer a viagem transatlântica de forma voluntária para os Estados Unidos. Ainda que naquela época eles não se identificassem como africanos porque as ilhas do Cabo Verde foram colonizadas por Portugal, chegaram aos Estados Unidos se identificando, em termos de nacionalidade e etnicidade, como portugueses. Mas, como não eram considerados brancos pelos membros da sociedade hospedeira, foram tratados como uma minoria racial e passaram a sofrer o mesmo tipo de discriminação que os afro-americanos enfrentavam. É por isso que o livro foi intitulado Between Race and Ethnicity. Portanto, eles têm um lugar muito importante na história americana. Por terem essas origens afro-portuguesas, ao chegarem ao final do século XIX e início do século XX, eles formaram a "primeira onda" de pioneiros imigrantes nãobrancos nos Estados Unidos. Houve uma nova onda de imigração temporária de cabo-verdianos posteriormente. Ainda estão chegando alguns, na parte sudeste do estado de Massachusetts.
Muitos outros estão imigrando para as vizinhanças de Boston, para Brockton, de modo que os locais de destino são diferentes dos do passado.

Existe, na sua opinião, uma especificidade cultural relevante, capaz de distinguir cada um dos grupos de imigrantes lusófonos da Nova Inglaterra, ou seja, brasileiros, portugueses e cabo-verdianos?

Existe um antigo conflito entre portugueses (açorianos) e cabo-verdianos. Os cabo-verdianos foram para os Estados Unidos no mesmo momento em que os portugueses tentaram se dissociar dos cabo-verdianos adotando para isso a raça como critério de diferenciação. Os portugueses não os consideravam bem-vindos nas igrejas, associações comunitárias, clubes de esportes e vida social açorianas. Por isso, os cabo-verdianos tiveram que fundar sua própria comunidade. Esse legado, baseado na cor e origem, foi marcante no início do século passado, quando a primeira onda de imigrantes aportou. Interessante observar que outra importante diferença foi a língua, pois os cabo-verdianos tinham sua própria língua portuguesa crioula. Com o passar do tempo, na segunda e terceira gerações de açorianos e cabo-verdianos - não havia brasileiros na época -, passou a existir maior integração, alguns casamentos, e algumas pessoas começaram a trabalhar juntas. Agora, temos uma população crescente de brasileiros chegando à região de Boston, e essa dinâmica é muito interessante de se observar, pois está se processando. E existem certas arenas nas quais brasileiros e cabo-verdianos realmente se encontram, que é a música. Existem muitas performances em que se apresentam bandas cabo-verdianas e brasileiras, como, por exemplo, no Dia de Portugal. Mas, sobretudo, as pessoas resistem a serem rotuladas como portuguesas ou como lusófonas. Elas querem, cada vez mais, ser reconhecidas pela sua nacionalidade distinta: "sou cabo-verdiano, não sou brasileiro", "sou brasileiro, não sou açoriano".

E em relação aos brasileiros e demais latinos? Os brasileiros tendem a ser rotulados de hispânicos. Nacionalidade e etnicidade podem ser considerados termos intercambiáveis?

Como socióloga, eu diria que os imigrantes brasileiros possuem a nacionalidade "brasileira", e eu poderia usar o termo "etnicidade" especialmente para falarmos da segunda geração, ou seja, crianças brasileiras nascidas nos Estados Unidos. Assim, a etnia da segunda geração será: "BrazilianAmerican", pois a etnicidade é um termo hifenizado.

Os termos "hispânico" e "latino" são normalmente usados de forma intercambiável nos Estados Unidos. Mas nunca pressuponho que os brasileiros se encaixem como hispânicos, já que eles são falantes de português. Prefiro o termo "latinos" a "hispânicos", quando me refiro a imigrantes da América do Sul, porque assim pelo menos abranjo os brasileiros.

\section{Mas você observa afinidades entre os dois grupos? \\ Esses dois termos, "hispânico" e "la- tino", são úteis para questões de go- verno, especialmente as demográficas, e para certas discussões de interesse público, mas abrangem tantas nacio- nalidades e culturas, além de línguas, que não posso generalizar o modo como se agrupam.}

Voltando aos cabo-verdianos, você os considera um grupo empreendedor? Seria possível comparálos aos brasileiros em relação ao empreendedorismo? 
Historicamente, os cabo-verdianos que vieram na primeira onda não eram empresários. Eles vieram como mão-de-obra, em baleeiros. Sofreram muita discriminação, trabalhavam na indústria de construção, nas docas carregando navios, e as mulheres, como arrumadeiras, domésticas, ou ainda na colheita de groselhas. Uns poucos iniciaram empresas próprias. Eram empresas típicas, como funerárias, salões de beleza, qualquer serviço pessoal em que as pessoas brancas não tivessem que chegar muito perto das minorias, de forma que um gerente branco de uma funerária não precisasse lidar com o corpo de um negro, um cabeleireiro branco não teria que tocar em um negro. Então, inicialmente era um tipo de reação discriminatória, mas que abriu as portas eles para estabelecerem suas próprias empresas. Entretanto, observo que as atuais correntes migratórias são muito mais voltadas ao empreendedorismo. Em Brockton, Massachusetts, muitos cabo-verdia- nos estão se fixando nas ruas centrais, onde se encontram atualmente 20 estabelecimentos cabo-verdianos, como restaurantes, mercearias, seguradoras, lojas de câmbio e agências de viagens. É interessante notar que os imigrantes vêm de todas as ilhas do Cabo Verde, mas os empresários vêm de uma ilha particular, com tradição empresarial. Dito isso, considerandose o número de empresas brasileiras existentes em Massachusetts, os brasileiros podem ser considerados mais empreendedores do que os cabo-verdianos. Mas, novamente, penso que isso está muito conectado com raça e classe social. Os brasileiros ainda ultrapassam os cabo-verdianos em recursos econômicos e financeiros. É muito mais fácil aos brasileiros, ainda que não documentados, alcançar a adaptação e algum sucesso nos Estados Unidos, porque eles podem ser considerados brancos. Existe menos discriminação, e eles podem se mudar para outras vizinhanças. Em Boston, os cabo-verdianos vivem nos bairros pobres de Dorchester, de Roxbury, onde outros afro-americanos e afro-caribenhos residem. Os brasileiros não vivem nesses bairros; eles estão nos subúrbios, em bairros muito mais receptivos para os brancos do que para os negros, e por causa disso têm mais oportunidades de sucesso.

Para finalizar, gostaria que você nos contasse sobre a sua experiência de trabalhar há tantos anos com o sociólogo Peter Berger.

Tem sido um grande prazer trabalhar com Peter Berger. Ele tem uma das mentes mais originais dentre as pessoas que conheci. Além de ser um pensador brilhante, é amigável e atencioso com aqueles que trabalham com ele. Particularmente, posso contatá-lo sempre que preciso. O fundamental é que, quando tenho uma idéia para discutir, ele vai direto ao ponto mais importante, sem rodeios, e isso é precioso para qualquer cientista social. Sinto-me afortunada por conviver com ele já há tantos anos.

\section{Traduzido por Wilson Fusco.}

Artigo convidado. Aprovado em 28.08.2006. 